\title{
Governador Valadares (MG) em Extensão: Interfaces para a Dinamização e Instrumentalização do Cenário Extensionista em um Campus Recém-Implantado Governador Valadares (MG) in extension: interfaces for the promotion and exploitation of the extension scenario in a newly deployed campus
}

\section{PALAVRAS-CHAVE \\ - Ensino Superior; \\ - Extensão Universitária; \\ - Formação Acadêmica e Profissional; \\ - Educação Médica.}

\section{KEYWORDS}

- Education, Higher;

- Community-Institutional Relations;

- Academic and Professional Training;

- Medical Education.
Recebido em: 30/03/2015

Aprovado em: 04/04/2016
Luiz Eduardo de Almeida ${ }^{I}$ Marília Nalon Pereira ${ }^{I}$ Valéria de Oliveira ${ }^{I}$

\section{RESUMO}

O presente estudo se propôs a analisar, por meio de um relato de experiência, a eficiência da implantação da "Oficina de instrumentalização e dinamização de projetos de extensão: a integração do ensino e da pesquisa científica em cenários extensionistas" como instrumento pedagógico indutor para a dinamização e instrumentalização dos espaços extensionistas do recém-implantado Campus Avançado-UFJF em Governador Valadares (MG). Após o percurso metodológico descrito, pôde-se concluir que a oficina se consagrou como um primeiro passo dado em direção ao reconhecimento da importância da extensão universitária para uma formação acadêmica mais contextualizada e voltada às aflições da população brasileira. Afinal, extensão é inserir vida no ensino superior, é dinamizar espaços em prol da coletividade.

\section{ABSTRACT}

This aim of the study was to use an experience report to analyze the efficiency of the implementation of the "Instrumentalization workshop and promotion of extension projects: the integration of education and scientific research in extension scenarios" as an educational tool for promoting and instrumentalizing extension spaces at the newly deployed Advanced Campus-UFJF, in Governador Valadares, MG. After using the described methodological approach, it may be concluded that this workshop was consecrated as a first step towards the recognition of the importance of university extension in more contextualized academic training that is oriented toward afflictions affecting the Brazilian population. Extension does, after all, mean inserting life into higher education and making spaces more dynamic for the public good. 


\section{INTRODUÇÃO}

Em 1988, a nova Constituição brasileira (p.35), consagrou o sistema tríplice como modelo formativo para o ensino superior, ao assegurar que: "as universidades [...] obedecerão ao princípio de indissociabilidade entre ensino, pesquisa e extensão"1.

A partir de então, neste ideológico arquétipo educacional, questiona-se: como se concretizaria a articulação da tríade formativa? Em teoria, neste cenário, o ensino é percebido como a reprodução do saber, a pesquisa como a ciência em movimento, e a extensão universitária como a concretização dos saberes gerados pelo ensino e/ou pesquisa. Na prática, no campo social, os espaços extensionistas socializam com a comunidade o resultado de um fato (pesquisa) ou de um aprendizado $(\text { ensino })^{2,3}$.

Adensando um pouco mais, no tocante à produção científica de uma universidade, tanto em quantidade quanto em qualidade, destaca-se sua direta relação com os aspectos integrados da educação. Afinal, quando ensino, pesquisa e extensão se juntam, um estimula a produção do outro ${ }^{2,3}$.

Pode-se afirmar que a extensão é o instrumento que efetiva, mediante experimentações e vivências, o sistema tríplice, consubstanciando-se como peça fundamental para uma formação profissional mais contextualizada e, principalmente, humanizada, e, por conseguinte, direcionada às reais necessidades da população brasileira ${ }^{4,5}$.

Entretanto, apesar da esperada e crucial cooperação entre ensino, pesquisa e extensão, a competição prevaleceu. De um lado, a pesquisa e o ensino têm sido alvo de discussões que originaram elaborados sistemas de avaliação da produção científica e da qualidade dos cursos; já a extensão universitária, por outro lado, não recebeu a mesma ênfase, nem sofreu as transformações necessárias em ritmo e intensidade pertinentes para acompanhar a evolução do ensino superior ${ }^{6}$.

Neste percurso, a importante produção gerada pela extensão é geralmente pouco valorizada no plano acadêmico, onde prevalecem os critérios e o ranking dos periódicos indexados. Embora abundante, a produção de textos de, ou sobre, extensão acaba frequentemente no esquecimento das gavetas, nos CDs, em subdiretórios de computadores ou mesmo em locais pouco visitados na $w e b^{4,5}$.

Diante deste cenário, lutando pelo aumento da visibilidade da extensão universitária, emergem no Brasil alguns espaços extensionistas. Periódicos de divulgação foram lançados e gradativamente vêm ganhando reconhecimento científico. Publicaram-se editais para financiamento de projetos, almejando sua solidificação no universo acadêmico. Além disso, a abertura de ambientes continuados de discussão - como a criação do Congresso Brasileiro de Extensão Universitária, com ações iniciadas em 2002 - agregou um público interessado em discutir os caminhos da extensão no Brasil e no mundo, constituindo um importante fórum de debates das instituições comunitárias, privadas e públicas ${ }^{7}$.

$\mathrm{O}$ presente estudo, metodologicamente estruturado em um relato de experiência, traz a vivência da coordenação do Curso de Odontologia do Campus Avançado de Governador Valadares da Universidade Federal de Juiz de Fora (UFJF-GV) no desenvolvimento da "Oficina de instrumentalização e dinamização de projetos de extensão: a integração do ensino e da pesquisa científica em cenários extensionistas". Nessa oficina, discutiu-se como inserir e desenvolver com qualidade a extensão universitária em um campus recém-implantado, sem descontextualizá-la das exigências de avaliação e valorização do conhecimento no contexto das universidades.

\section{DINAMIZANDO OS CENÁRIOS EXTENSIONISTAS: TEORIZANDO, PRATICANDO E CRITICANDO}

Trata-se de um relato de experiência moldado segundo a técnica qualitativo-descritiva e estruturado sob estratégia narrativa - qualitativo-descritivo, pois compreende um conjunto de diferentes técnicas interpretativas que visam descrever e decodificar os componentes de um sistema complexo de significados; narrativa, por combinar as percepções do pesquisador aos acontecimentos apreciados no estudo, calcadas em princípios críticos e reflexivos que consideram (ou pelo menos fazem inferência) as subjetividades das vivências experimentadas ${ }^{8,9}$.

O Campus Avançado da Universidade Federal de Juiz de Fora (UFJF) foi implantado no município de Governador Valadares (MG). O primeiro Campus Avançado da UFJF foi aprovado em 16 de fevereiro de 2012 pelo seu Conselho Superior, trazendo como expectativa o desenvolvimento para a região leste de Minas Gerais por meio da instalação de nove cursos de bacharelado - Administração, Ciências Contábeis, Ciências Econômicas, Direito, Farmácia, Fisioterapia, Medicina, Nutrição e Odontologia -, cujas aulas se iniciaram no segundo semestre letivo de $2012^{10}$. Destaca-se ainda a confirmação do décimo curso, Educação Física/bacharelado, também aprovado, em novembro de 2013, pelo Conselho Superior da UFJF e implantado no primeiro semestre letivo de $2014^{11}$.

Paralelamente, apesar de reconhecer a implantação de um campus avançado como um grande desafio, a Coordenação do Curso de Odontologia da UFJF-GV (CCO/UFJF-GV) via nesse momento uma grande oportunidade, talvez única, de aplicar um instrumento indutor para a efetivação da indissociabilidade da formação acadêmica. Para isto, foi estruturada a "Oficina de instrumentalização e dinamização de projetos de extensão: a integração do ensino e da pesquisa científica em 
cenários extensionistas", direcionada aos até então dois únicos projetos de extensão que contavam com acadêmicos de Odontologia em sua equipe extensionista:

- "Equipe Sala de Espera: trabalho multiprofissional em Unidades de Atenção Primária à Saúde (Uaps) de Governador Valadares";

- "Atenção preventiva e educativa em saúde para pessoas com transtornos de desenvolvimento e seus familiares na Apae de Governador Valadares".

A oficina foi delineada pela CCO/UFJF-GV, e seu conteúdo, com carga horária total de quatro horas, foi didaticamente dividido em duas etapas complementares (contextualização dos projetos de extensão, 1 hora; planejamento estratégico da extensão, 3 horas), desenvolvidas, respectivamente, nos dias 10 e 29 de janeiro de 2014 na Faculdade de Odontologia UFJF/GV.

Na primeira etapa, após as exposições dos projetos de extensão por seus coordenadores, foram identificadas algumas coincidências entre as propostas extensionistas: ambas estavam em processo de instalação em seus cenários de atuação, além de carregarem como estratégia de dinamização a implantação de ações de educação em saúde, a serem executadas continuadamente por equipes multiprofissionais compostas por discentes e docentes de diversas áreas de formação (enfoques em Farmácia, Fisioterapia, Medicina, Nutrição e Odontologia).

Em síntese, deste cenário extensionista, em confronto com a literatura científica, três pontos positivos merecem ser evidenciados. Em primeiro lugar, consagra-se positivamente a implantação de ações educativo-preventivas como instrumento para dinamizar os espaços referenciados. Afinal, a educação em saúde constitui um dos pilares da promoção de saúde, que visa capacitar e dar oportunidade às pessoas para que exerçam controle e melhoria sobre sua saúde, ou seja, em um modelo de autonomia e empoderamento ${ }^{12}$. Diversos estudos relatam a eficiência e a eficácia desta estratégia na dinamização de espaços coletivos $^{13-17}$

Outro ponto positivo identificado nos dois projetos foi a organização de trabalho atrelada a vários enfoques profissionais. Nesta perspectiva, em uma equipe multiprofissional, a articulação se refere à recomposição de processos de trabalho distintos e, portanto, à consideração de conexões e interfaces entre as intervenções técnicas peculiares de cada área profissional $^{18}$. E, ainda, trabalhar em equipe de modo integrado significa conectar diferentes processos de trabalho com base no conhecimento do trabalho do outro e na valorização da participação deste na produção de cuidados. Significa construir consensos quanto aos objetivos e resultados a serem alcançados pelo conjunto de profissionais, e quanto à maneira mais adequada de adquiri-los. Significa também utilizar as interações entre os agentes envolvidos, com vistas ao entendimento e ao reconhecimento recíproco de autoridades de saberes e da autonomia técnica ${ }^{19}$.

Um terceiro ponto positivo evidenciado refere-se aos cenários extensionistas a serem assistidos pelos referidos projetos de extensão. A sala de espera justifica-se por ser um território dinâmico, onde diferentes indivíduos se mobilizam aguardando seu atendimento de saúde. É um lugar público, onde as pessoas conversam, trocam experiências, observam-se, emocionam-se e se expressam, ou seja, um local descrito pelas pluralidades econômicas, sociais e culturais, além de suas subjetividades. Diante deste rico cenário, vale enfatizar que este território constitui um espaço fértil para implantar ações educativas, que podem contribuir significativamente para a promoção da saúde, prevenção de agravos e encaminhamento a outras atividades ${ }^{20-24}$. No tocante às ações de educação em saúde em instituições destinadas a pessoas com transtornos de desenvolvimento, bem como seus familiares, estudos são categóricos quanto aos benefícios trazidos por estas ações ${ }^{25-31}$. Desta forma, pode-se inferir que intervir nos cenários enfocados é prover o estreitamento do enlace entre ensino e sociedade, e desta forma capacitar os futuros profissionais a conduzirem sua formação em direção das reais e urgentes necessidades da população brasileira.

Entretanto, apesar das descrições otimistas supracitadas, foi discernida uma característica altamente fragilizadora nos dois projetos: o formato do desenvolvimento das ações programadas. Os ideais dos projetos ainda estavam centrados no desenvolvimento da extensão pelo viés da "via de mão única". Tudo é focado nos ensejos paternalistas da universidade, que vai à sociedade levar algo de sua especialidade. Nesta forma de trabalho, os indivíduos são percebidos como receptores, e as ações normalmente são idealizadas no molde de assistencialismo, palestras, eventos ou prestação de serviço ${ }^{4,5,32}$. Em geral, esta sistemática extensionista é instrumentalizada pela perspectiva biologicista do trabalho em saúde, descaracterizada do olhar social.

Avigorando estes argumentos, por meio da análise de Freire $^{33}$, pode-se afirmar que a extensão universitária se torna antidialógica e manipuladora quando associada ao desconhecimento cultural da população assistida. O mesmo autor ainda complementa a importância da quebra da verticalidade, "da coisificação do ser humano", onde um ator é sujeito e o outro objeto, em prol de uma relação em que todos possam ser sujeitos atuantes, que agem e pensam criticamente. 
Pode-se ainda afirmar que este problema serviu de gatilho para outro ponto negativo: a não interface do cenário extensionista com as modalidades de ensino e pesquisa. Afinal, a indissociabilidade entre estas modalidades só se dá quando a extensão se define como uma "via de mão dupla": além de levar informações para a comunidade (ensino), ela traz para o cenário universitário dados e informações, coletados e interpretados cientificamente (pesquisa), que retratam as experiências vivenciadas e, principalmente, contextualizadas na integralidade da vida humana por meio dos cenários extensionistas $3,4,5,32,34$

Estas reflexões tornam-se vivas com algumas transcrições coletadas durante a primeira etapa da oficina:

Extensão é muito mais complexo do que imaginava...

(M.A.S.V.)

Nossa, preciso rever meus conceitos... (N.R.C.C.)

Será que vou dar conta?! (K.A.M.Z.)

Teremos que repensar muitas coisas... (P.S.A.S.)

Projeto de extensão dá muito trabalho... (G.F.M.A.)

Entrelaçado a estas indagações, encerrou-se o primeiro encontro (I. Contextualização dos projetos de extensão, 1 hora), que trouxe subsídios importantíssimos para melhor direcionar a aplicabilidade do segundo módulo da oficina, haja vista as inquietações dos extensionistas estarem centradas e direcionadas a um importante questionamento: "como fazer extensão?".

Assim, pontua-se a importância de discutir modelos estratégicos voltados ao desenvolvimento da extensão universitária. Em planos maiores, pode-se dizer que planejar em extensão é garantir sua plena articulação com as modalidades de ensino em pesquisa, formando um círculo virtuoso, no qual a pesquisa sustenta o ensino, que sustenta a extensão, que retroalimenta a pesquisa e o ensino. Segundo este entendimento, acredita-se que o planejamento estratégico articulado ao modo de se trabalhar na extensão aperfeiçoaria a forma de atuar nos cenários extensionistas, em que a extensão é percebida como espaço para gerar conhecimentos tanto práticos como teóricos, uma vez que serve como campo para pesquisas e aprimoramento das metodologias utilizadas no ensino superior $^{5,32,35,36,37}$.

De acordo com estes preceitos, pautou-se o conteúdo da segunda parte da oficina (II. Planejamento estratégico da extensão, 3 horas), ministrado em aula expositiva. Mediante metodologias ativas/problematizadoras, foi apresentada aos integrantes dos projetos de extensão uma estratégia para dinamizar e instrumentalizar ações de educação em saúde em cenários extensionistas, estrategicamente, em interface com ensino e pesquisa.

As metodologias ativas, segundo Freire ${ }^{33}$, estão apoiadas em um princípio teórico significativo, "a autonomia", que, segundo as reflexões de Almeida ${ }^{4}$ e Fernandes et al. ${ }^{38}$, em conexão com o processo formativo dos cursos de saúde, tem sua intencionalidade alicerçada numa formação capaz de desenvolver no discente o horizonte de aprender a aprender, englobando neste movimento o conhecer, o fazer, o viver junto e, sem dúvida, o aprender a ser, garantindo aos futuros profissionais da saúde a capacitação da autonomia e do discernimento para assegurar a integralidade da atenção à saúde com eficiência, eficácia e, principalmente, de forma contextualizada e humanizada

O instrumento apresentado pela CCO/UFJF-GV se desenvolve em três etapas: Teorizando ("o pensar"), Praticando ("o fazer") e Criticando ("o refletir"), sendo por isso denominado TPC (Anexo). Sistematicamente, as etapas se complementam, trazendo em seu bojo conceitual a importância de estabelecer a relação entre eficiência e eficácia de ações de educação em saúde com planejamento estratégico (Figura 1). Estudos corroboram a importância de planejar em saúde. Apenas boas ideias não bastam, é fundamental saber desenvolver meios para viabilizá-las, evitando que possíveis desafios e ameaças, que na realidade são comuns, comprometam ou até inviabilizem a execução de grandes ações. Em suma, uma equipe preparada é aquela capaz de gerar estratégias e soluções para contornar possíveis obstáculos ${ }^{5,36,37}$.

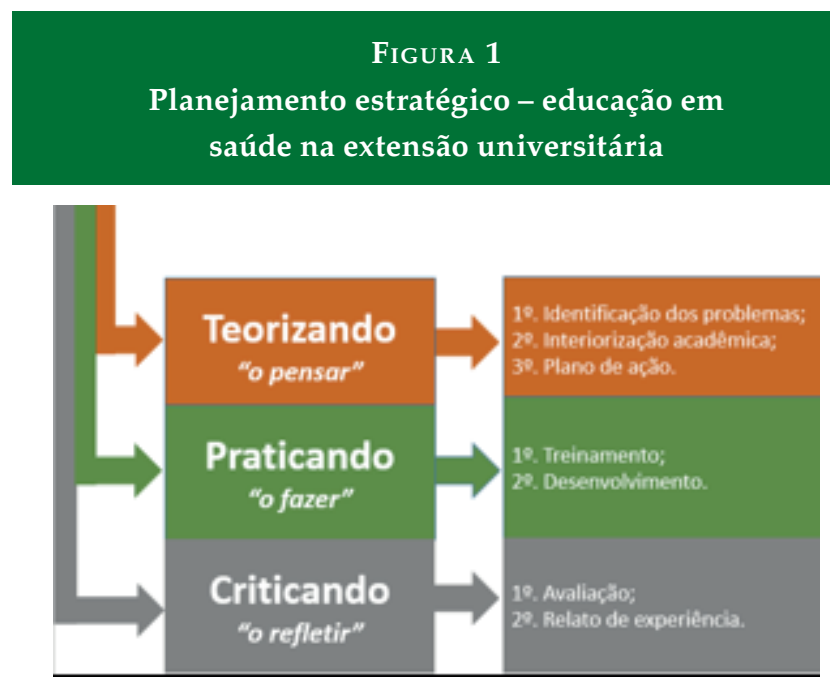

Na primeira etapa estratégica, Teorizando ("o pensar"), três pontos foram levantados e discutidos. $\mathrm{O}$ primeiro foi a 
“identificação do(s) problema(s)", normalmente burlado durante a construção e desenvolvimento de projetos de extensão, gerando, por consequência, um modelo assistencialista, paternalista e descontextualizado do controle social. No intento de minimizar esta fragilidade, buscou-se neste espaço reposicionar os membros dos projetos de extensão em seu principal papel, o de "facilitador". Nestes moldes, a equipe extensionista não identifica isoladamente os problemas; pelo contrário, ela o faz juntamente com as comunidades assistidas, empoderando-as ao se verem como agentes proativos em suas responsabilidades individuais e coletivas em prol da melhoria da qualidade de suas próprias vidas.

Identificado(s) o(s) problema(s), passou-se ao ponto seguinte, a "interiorização acadêmica". Discorreu-se neste momento sobre a dicotomia problema-solução. No tocante ao problema, destacou-se a importância de os extensionistas levantarem conteúdos já desenvolvidos em salas de aula e/ou disponíveis em bases bibliográficas científicas e que expliquem e descrevam a relação causa-consequência do(s) problema(s) levantado(s). Quanto à solução, materializa-se aqui na descrição dos objetivo(s) e meta(s) a alcançar, delimitando-se, assim, os resultados esperados.

Até aqui, do relatado, desprendem-se dois eixos: o primeiro (imagem-espelho), que retrata o(s) problema(s) a ser(em) vencido(s), e o segundo (imagem-objetivo), que descreve o(s) resultado(s) esperado(s). Entretanto, como prover o deslocamento entre esses eixos? Ou melhor, como deslocar as imagens de espelho para objetivo? Junto a este propósito evidenciou-se a importância de equipes extensionistas estarem aptas a desenvolver planos de ação, pois, afinal, transformar uma realidade não é tarefa simples.

Tendo em vista esta necessidade e pensando nas demandas da extensão como espaços complexos, visto não retratarem mimetizações da realidade, propôs-se um questionário direcionador e estratégico para elaborar um plano de ação. Estruturado em oito questões - "O quê?", "Quem?", "Onde?", "Quando?", “Como?", “Quanto custa?", "Por quê?" e "Como avaliar?" -, esse instrumento traz em sua operacionalidade a construção de um plano de ação mais consoante com as representatividades dos campos de atuação da extensão universitária, ou seja, aproxima-se o máximo possível das integralidades imbuídas nos problemas identificados. Deste modo se encerra a primeira etapa estratégica, Teorizando / "o pensar".

Chega, então, o momento de desenvolver o que se planejou. A etapa Praticando / "o fazer" permite que o plano de ação traçado seja experimentado/vivenciado de forma gradual, organizada, permitindo maior eficiência dos atores envolvidos e, principalmente, maior eficácia das medidas a adotar.
Didaticamente, este período é dividido em duas partes: treinamento e desenvolvimento. Treinar antes de implantar o plano de ação consiste em conscientizar, contextualizar e capacitar toda a equipe em seus respectivos papéis, otimizando os recursos humanos envolvidos. Durante o treinamento, pode haver muitas discussões e até mesmo modificações. Assim, este momento se encerra com a aprovação do plano de ação final.

Colocar em prática tudo o que foi planejado e treinado é a fase de desenvolvimento. Este momento evidencia o enlace universidade-sociedade, conscientizando o acadêmico de seu real e fundamental papel diante das verdadeiras necessidades da população brasileira o mais precocemente possível. Nesse contexto, vale destacar que, por mais bem treinada que seja, a equipe deve estar preparada para as plasticidades momentâneas, pois é praticamente impossível ter o controle total de todo o processo em um cenário real. No tocante aos dados e informações a serem coletados, revela-se ainda a importância de capacitar os acadêmicos a não se basearem apenas nos instrumentos construídos, despertando nos discentes um olhar mais ampliado para as subjetividades impressas no meio dinâmico e vivo em que estão inseridos, a fim de que produzam uma análise pautada em dados quantitativos e/ou qualitativos.

A última etapa, Criticando / "o refletir", talvez uma das principais deste ciclo, faz referência à avaliação e à construção do relato de experiência. É neste espaço que a equipe de desenvolvimento de projetos de extensão consagra seus feitos de forma positiva, negativa ou inconclusiva. Para isso, utilizará análises e interpretações, objetivas e/ou subjetivas, das vivências experimentadas. Por fim, reconhecendo o universo da extensão como inesgotável para a aplicação dos conceitos disseminados em sala de aula e para o alicerce da pesquisa, é fundamental que as experimentações extensionistas sejam compartilhadas, reconhecendo-se na publicação científica um dos mais importantes instrumentos de divulgação. Entre as diversas metodologias, destaca-se o "relato de experiência", ressaltando que sua construção não deve ser direcionada apenas aos acertos, ou seja, deve-se oferecer espaço também para discutir erros e fragilidades, já que uma equipe aprende com os acertos e se transforma com os erros.

A construção do presente instrumento foi calcada na prerrogativa de observar a extensão como um cenário vivo e dinâmico. Assim, a sistemática da "Oficina de instrumentalização e dinamização de projetos de extensão: a integração do ensino e da pesquisa científica em cenários extensionistas" foi pensada segunda uma perspectiva ativo-problematizadora. Essa forma de aprendizado favorece o desenvolvimento de habilidades de observação, análise, avaliação, cooperação entre os membros do grupo e superação de conflitos, além de 
possibilitar o desenvolvimento de tecnologias culturalmente compatíveis ${ }^{39,40,41}$.

\section{CONSIDERAÇÕES FINAIS}

Tendo como contexto um campus avançado recém-implantado, a Coordenação do curso de Odontologia da UFJF/GV, preocupada com a construção dos seus espaços extensionistas, idealizou e desenvolveu a "Oficina de instrumentalização e dinamização de projetos de extensão: a integração do ensino e da pesquisa científica em cenários extensionistas". Entre as conquistas alcançadas por este instrumento pedagógico, destacam-se:

- a inserção de ações extensionistas, por parte da UFJF-GV, na cidade de Governador Valadares (MG), voltadas a atender às demandas da sociedade local;

- o reconhecimento do importante papel da extensão no processo formativo dos futuros profissionais de saúde;

- a diferenciação da metodologia apresentada como um instrumento indutor para sensibilizar e direcionar os idealizadores e integrantes desses Projetos de Extensão a desenvolvê-los segundo a perspectiva da indissociabilidade, ou seja, consubstanciá-los entre os elos ensino, pesquisa e extensão;

- a conscientização dos envolvidos com extensão de que suas responsabilidades não se encerram em seus espaços de campo, estendendo-se aos cenários científicos e, assim, afirmando o enlace ensino-comunidade;

- a valorização da divulgação das vivências extensionistas nos espaços científicos.

Assim, não para concluir, mas para desafiar, acredita-se que este estudo contribui para mostrar a importância da extensão universitária para uma formação acadêmica mais contextualizada e, de fato, voltada à solução das aflições que assolam a população brasileira. Afinal, extensão é inserir vida no ensino superior, é dinamizar espaços em prol da coletividade.

\section{REFERÊNCIAS}

1. Brasil. Senado Federal. Constituição da República Federativa do Brasil, texto promulgado em 05 de outubro de 1988. Brasília, 1988. Disponível em: <http:/ / www.senado. gov.br/legislacao/const/con1988/CON1988_05.10.1988/ CON1988.pdf>. Acessado em 15 de fev. 2015.

2. Brasil. Rede Nacional de Extensão Universitária. Plano Nacional de Extensão Universitária. Brasília, 2001. Disponível em: <http:/ / www.portal.ufpa.br/docsege/Planonacionaldeextensaouniversitaria.pdf $>$. Acessado em 15 de fev. 2015.
3. Carvalho ACP, Kriger L. Educação Odontológica. 1a edição. São Paulo: Artes Médicas, 2006.

4. Almeida LE Análise descritiva da disciplina "Seminário para sensibilização da importância do acolhimento e enfoque humanizado": uma integração entre a Faculdade de Odontologia - UFJF e o Pró-Saúde. Juiz de Fora; 2010. Mestrado (Dissertação) - Universidade Federal de Juiz de Fora.

5. Almeida LE, Pereira MN, Bara EF. Projeto de Extensão Sabiá: a introdução de uma prática integralizadora no ensino odontológico. In: Almeida LE, Pereira MN, Carmo AMR, Bara EF, Devito KL, Chaves MGAM, Chaves Filho HDM. Pró-Saúde: Ensino, Pesquisa e Extensão. Juiz de Fora: Editar Juiz de Fora, 2009b. p.126-64.

6. Silva MS, Vasconcelos SD. Extensão Universitária e Formação Profissional: avaliação da experiência das Ciências Biológicas na Universidade Federal de Pernambuco. Estudos em Avaliação Educacional. 2006.17(33) [capturado em: 15 de fev. 2015];119-136. Disponível em: <http:/ / www.fcc. org.br/pesquisa/publicacoes/eae/arquivos/1280/1280. pdf $>$.

7. Congresso Brasileiro de Extensão Universitária, CBEU. Fórum de Pró-Reitores de Extensão das Universidades. Anais: I Congresso Brasileiro de Extensão Universitária - Universidade: conhecimento e inclusão social / II Encontro Nacional de Avaliação Institucional de Extensão Universitária. João Pessoa, Paraíba, Novembro de 2002. Disponível em: <http://www.prac.ufpb.br/anais/Icbeu_ anais/anais/resumos/abertura.pdf $>$. Acessado em 15 de fev. 2015.

8. Bell J. Projeto de Pesquisa - Guia para pesquisadores iniciantes em educação, saúde e ciências sociais. Porto Alegre: Editora Artmed; 2008.

9. Creswell JW. Projeto de Pesquisa - Métodos qualitativo, quantitativo e misto. Porto Alegre: Editora Artmed; 2007.

10. Universidade Federal de Juiz de Fora, UFJF. Secretaria de Comunicação. UFJF abrirá campus avançado em Governador Valadares com 750 vagas em 9 cursos. Juiz de Fora, Minas Gerais, 28 de fevereiro de 2012. Disponível em: <http:/ / www.ufjf.br/secom/2012/02/28/ufjf-abrira-campus-avancado-em-governador-valadares/>. Acessado em 15 de fev. 2014.

11. Universidade Federal de Juiz de Fora, UFJF. Secretaria de Comunicação. UFJF expande curso de Educação Física para Governador Valadares. Juiz de Fora, Minas Gerais, 22 de novembro de 2013. Disponível em: < http:/ / www.ufjf. br/secom/2013/11/22/ufjf-expande-curso-de-educacao-fisica-para-governador-valadares/>. Acessado em 15 de fev. 2014. 
12. Mialhe FL, Silva CMC, Cunha RB, Possobon RF. Educação em Saúde. In: Tratado de Saúde Coletiva em Odontologia. Nova Odessa: Editora Napoleão; 2009. p.441-486.

13. Brasil. Ministério da Saúde. Política Nacional de Promoção da Saúde. Brasília: Ministério da Saúde; 2006.

14. Carneiro ACLL, Souza V, Godinho LK, Fara ICM, Silva KL, Gazzinelli MF. Educação para a promoção da saúde no contexto da atenção primária. Rev Panam Salud Publica [online]. 2012;31(2):115-120. Disponível em: <http:/ / www. scielosp.org/scielo.php?script=sci_arttext\&pid=S1020$-49892012000200004 \& \operatorname{lng}=p t \& n r m=i s o>$. ISSN 1020-4989. http: / / dx.doi.org/10.1590/S1020-49892012000200004>. Acessado em 16 de fev. 2015.

15. Carvalho SR. As contradições da promoção da saúde em relação à produção de sujeitos e a mudança social. Cienc Saude Coletiva.2004;9(3):669-78.

16. Fontes BA, Lima R, Lima JA. Promoção de saúde e participação social: o modelo de atenção básica do Sistema de Saúde Brasileiro. Cienc Soc Unisinos. 2010;46(1):65-79.

17. Heidmann ITSB, Almeida MCP, Boehs AE, Wosny AM, Monticelli M. Promoção à saúde: trajetória história de suas concepções. Texto Contexto Enferm. 2006;1(2):352-8.

18. Ciampone MHT, Peduzzi M. Trabalho em equipe e trabalho em grupo no Programa de Saúde da Família. Rev. Bras. Enferm.2000;53(Esp.):143-147.

19. Ribeiro EM, Pires D, Blank VLG. A teorização sobre o processo de trabalho em saúde como instrumental para a análise do Programa de Saúde da Família. Cad Saúde Pública.2004;20(2):438-446.

20. Brondani JE, Aranda AL, Morin VL, Ferraz TR, Colomé CLM, Fedosse E. Percepções de gestantes e puérperas acerca da sala de espera em uma Unidade Básica de Saúde integrada à Estratégia Saúde da Família. Rev Bras Promoção Saúde.2013;26(1):63-70.

21. Colomé CLM, Landerdahl MC. Sala de Espera: Espaço para a (Re)Construção do conhecimento em Saúde. In: Nietsche EA, organizadora. O processo educativo na formação e na práxis dos profissionais da saúde: desafios, compromissos e utopias. Santa Maria: UFSM; 2009.

22. Nora CRD, Mânica F, Germani ARM. Sala de espera uma ferramenta para efetivar a educação em saúde. Revista Saúde e Pesquisa. Maringá. 2009; 2(3):397-402.

23. Rodrigues AD, Dallanora CR, Rosa J, Germani ARM. Sala de espera: um ambiente para efetivar a educação em saúde. Vivências. Online. 2009.5(7) [Capturado em: 12 fev. 2015];101-106. Disponível em: <http://www.reitoria. uri.br/ vivencias /Numero_007/artigos/artigos_vivencias_07/Artigo_13.pdf $>$.
24. Teixeira ER, Veloso RC. O grupo em sala de espera: território de práticas e representações em saúde. Texto Contexto Enferm. Florianópolis. 2006;15(2):320-5.

25. Abreu MHNG, Castilho LS, Resende VL. Assistência odontológica a indivíduos portadores de deficiências: o caso da Associação Mineira de Reabilitação e Escola Estadual João Moreira Salles. Arq Odontol. 2001;37(2):153-61.

26. Duailibi SE, Duailibi MT. Odontologia para pacientes especiais- Uma nova visão sobre conceito e classificação em pacientes especiais. Rev Paul Odontol. 1998;20(2): 28-33.

27. Grunsven MFV, Cardoso EBT. Atendimento odontológico em crianças especiais. Rev Assoc Paul Cir Dent.1995;49(5):364-70.

28. Resende VLS, Castilho LS, Souza ECV, Jorge WV. Atendimento odontológico a pacientes com necessidades especiais. In: 8o Encontro de Extensão da UFMG: 2005 Belo Horizonte. Anais do $8^{\text {o }}$ Encontro de Extensão da UFMG; 2005. p.1-6.

29. Toledo AO, Bezerra ACB. Odontologia preventiva para excepcionais. In: Fourniol Filho A. Pacientes especiais e a Odontologia. 1. ed. São Paulo: Santos;1998. p.423-32.

30. Tomita NE, Fagote BF. Programa educativo em saúde bucal para pacientes especiais. Odontol Sociedade. 1999;1(1/2):45-50.

31. Uemura ST, Ramos L, Esposito D, Uemura AS, Boccia MF, Mugayar LRF. Motivação e educação odontológica em pacientes especial. RGO. 2004; 52(2):91-100.

32. Melo Neto JF. Extensão universitária: uma análise crítica. João Pessoa: Editora Universitária UFPB; 2001.

33. Freire P. Pedagogia da Autonomia: saberes necessários à pratica educativa. 34.ed. São Paulo: Paz e Terra; 2006.

34. Barbosa VC. Extensao universitaria: proposicao e validacao de um Instrumento de avaliação da percepção dos discentes. Santo Antônio de Jesus; 2012. Mestrado [Dissertação] - Faculdade de Ciencias Empresariais.

35. Thiollent M, Araújo Filho T, Soares RLS. Metodologia e experiências em projetos de extensão. Niterói: EDUFF; 2000. $341 \mathrm{p}$.

36. Almeida LE, Pereira MN, Bara EF. Programa de Capacitação de Ideias (PCI). In: Almeida LE, Pereira MN, Carmo AMR, Bara EF, Devito KL, Chaves MGAM, Chaves Filho HDM. Pró-Saúde: Ensino, Pesquisa e Extensão. Juiz de Fora: Editar Juiz de Fora; 2009. p.165-91.

37. Campos FCC, Faria HP, Santos MA. Planejamento e Avaliação das Ações de Saúde. 2ª edição. Belo Horizonte: NESCON/UFMF; Coopmed, 2010.

38. Fernandes JD, Xavier IM, Ceribelli MIPF, Bianco MHC, Maeda D, Rodrigues MVC. Diretrizes curriculares e estra- 
tégias para implantação de uma nova proposta pedagógica. Rev Esc Enferm USP. 2005;39(4):443-9.

39. Freire P. Extensão ou Comunicação. 13.ed. São Paulo: Paz e Terra; 2006.

40. Freire P. Educação como Prática da Liberdade. $30^{a}$ Edição. Rio de Janeiro: Paz e Terra; 2007.

41. Piaget J. A linguagem e o pensamento na criança. 1.ed. Rio de Janeiro: Fundo de Cultura; 1973.

\section{CONTRIBUIÇÃO DOS AUTORES}

Todos os autores participaram na idealização e no desenvolvimento do estudo, que se encerrou na construção do presente artigo científico.

\section{CONFLITO DE INTERESSES}

Os autores declaram não haver conflito de interesses.

\section{ENDEREÇOS PARA CORRESPONDÊNCIA}

Luiz Eduardo de Almeida

Rua Cícero Siqueira, 22/apto 202

Esplanada - Governador Valadares

CEP: 35020-110 - MG

E-mail: luiz.almeida@ufjf.edu.br 